TERRA. Revista de Desarrollo Local e-ISSN: 2386-9968

Número 6 (2020), 343-349

DOI 10.7203/terra.6.16781

IIDL - Instituto Interuniversitario de Desarrollo Local

\title{
Reseña. El paper dels ajuntaments pel desenvolupament de les àrees rurals. Creerse el desarrollo local
}

\author{
Buenaventura Marco Moreno \\ Graduado en Ciencias Políticas y de la Administración Pública (Universitat de \\ València, España) \\ buemarmo@alumni.uv.es
}

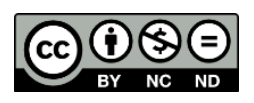

Esta obra se distribuye con la licencia Creative Commons Reconocimiento-NoComercial-SinObraDerivada 4.0 Internacional 


\section{SECCIÓN RESEÑAS}

\section{Reseña. El paper dels ajuntaments pel desenvolupament de les àrees rurals. Creerse el desarrollo local}

Resumen: En la presente reseña se tratará de ofrecer una breve crónica de las intervenciones que tuvieron lugar en las jornadas organizadas por el Ayuntamiento de Algímia d'Alfara el pasado viernes 29 de noviembre de 2019 bajo el título "El paper del ajuntaments pel desenvolupament de les àrees rurals". Así, se tratará en lo sucesivo de demostrar que, sin perjuicio de la plétora de buenas prácticas compartidas por los ponentes, hubo una idea que brilló por encima del resto durante toda la jornada, esto es: que el desarrollo local es un acto de creencia, de volición, una creación ex novo que la ciudadanía sólo puede llevar a cabo cuando se contagia de la esperanza y la voluntad de aquel o aquella que actúa como sí éste no pudiera no funcionar. Evidentemente, hablamos de los agentes de desarrollo local, pero no sólo.

Palabras clave: desarrollo local, gobernanza, participación, espacios rurales, Algimia d'Alfara (Valencia).

Recibido: 04 de marzo de 2020

Devuelto para revisión: -

Aceptado: 05 de marzo de 2020

\section{Referencia / Citation:}

Marco, B. (2020). Reseña. El paper dels ajuntaments pel desenvolupament de les àrees rurals. Creerse el desarrollo local. TERRA. Revista de Desarrollo Local, (6), 343-349. DOI 10.7203/terra.6.16781 


\section{Excmo. Ayto. de Algimia d'Alfara (Valencia)}

\section{EL PAPER DELS AJUNTAMENTS PER DESENVOLUPAMENT DE LES ÀREES RURALS. CREERSE EL DESARROLLO LOCAL}

Algimia d'Alfara (Valencia). Viernes, 29 de noviembre de 2019. Casa de la Cultura. De $09 \mathrm{~h} 00$ a $18 \mathrm{~h} 00$.

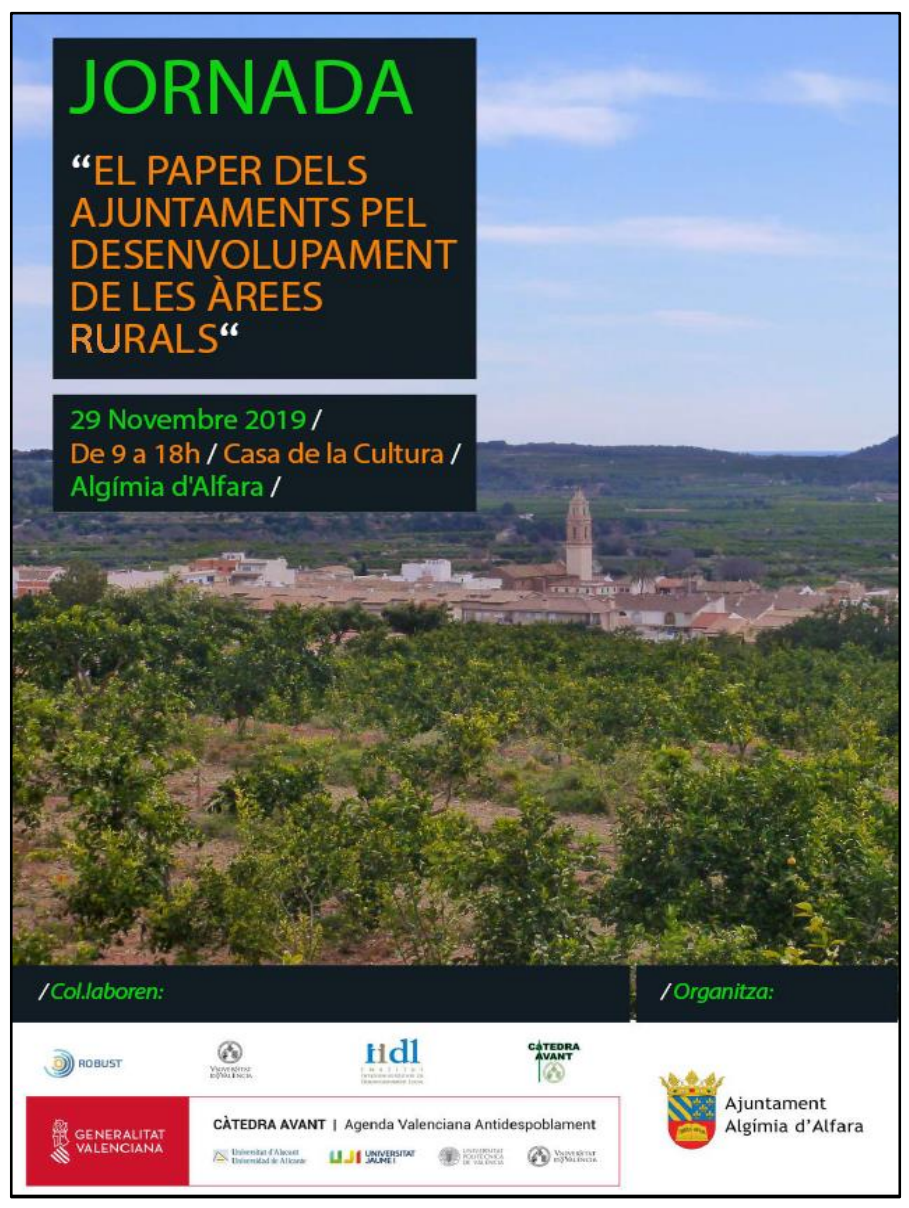
ciudadanía sólo puede llevar a cabo cuando se contagia de la esperanza y la voluntad de aquel o aquella que actúa como sí éste no pudiera no funcionar. Evidentemente, hablamos de los agentes de desarrollo local, pero no sólo.

Así, inauguró las jornadas el profesor de la Universitat de València y miembro del Instituto Interuniversitario de Desarrollo Local y de la Càtedra Avant Jaime Escribano, con una ponencia titulada "La Administración local como impulsora del desarrollo local". Ésta dio comienzo con la constatación de que, en esencia, ante la complejidad del trasfondo normativo y los problemas de financiación, aquellos que están en mejores condiciones para implementar propuestas de Acción en el territorio, esto es, los municipios, afrontan hoy los mismos problemas que en 2006. Y sin embargo el profesor Escribano recordó que «tenemos derecho a unos servicios públicos - y, sobre todo- de calidad, vivamos donde vivamos», algo que no siempre se cumpliría debido a la dependencia de éstos de las ratios. De esta forma, la aplicación de ratios como el que establece que deba haber un fisioterapeuta por cada 10.000 habitantes convierten en tareas imposibles, no sólo el hecho de reunir esa población, sino de dónde localizar al especialista una vez se hubiera conseguido y en qué día y hora pasaría consulta. De igual

Más extraño y más puro que cosa producida por sugestión, el objeto aducido por la esperanza.

(Borges, 2004:33).

En la presente reseña se tratará de ofrecer una breve crónica de las lugar en las jornadas organizadas por el Ayuntamiento de Algímia d'Alfara el pasado viernes 29 de noviembre de 2019 bajo el título "El paper del ajuntaments pel desenvolupament de les àrees rurals". Así, se tratará en lo perjuicio de la plétora de buenas prácticas compartidas por los ponentes, hubo una idea que durante toda la jornada, esto es: que el desarrollo local es un acto de creencia, de volición, una creación ex novo que la 
forma, la fiscalidad para empresas no está pensada para núcleos de población menores de 5.000 habitantes, y las ayudas a segundas residencias no tienen en cuenta que quizás para el medio rural sean más necesarias aquella para primeras residencias de jóvenes. En estas condiciones de escasa adaptación del marco normativo al entorno rural, la única manera de superar la dicotomía rural-urbano será, según Escribano, trabajar en redes, la cooperación y la innovación, entendida esta última como la búsqueda de respuesta a una necesidad. Huelga decir, como nos recordó el ponente, que esta actitud de «juntos sumamos más» requiere un cambio cultural, un entorno de confianza, y - haciendo acto de presencia por primera vez en la jornada una expresión que se repetiría una y otra vez«claro, todo esto hay que creérselo».

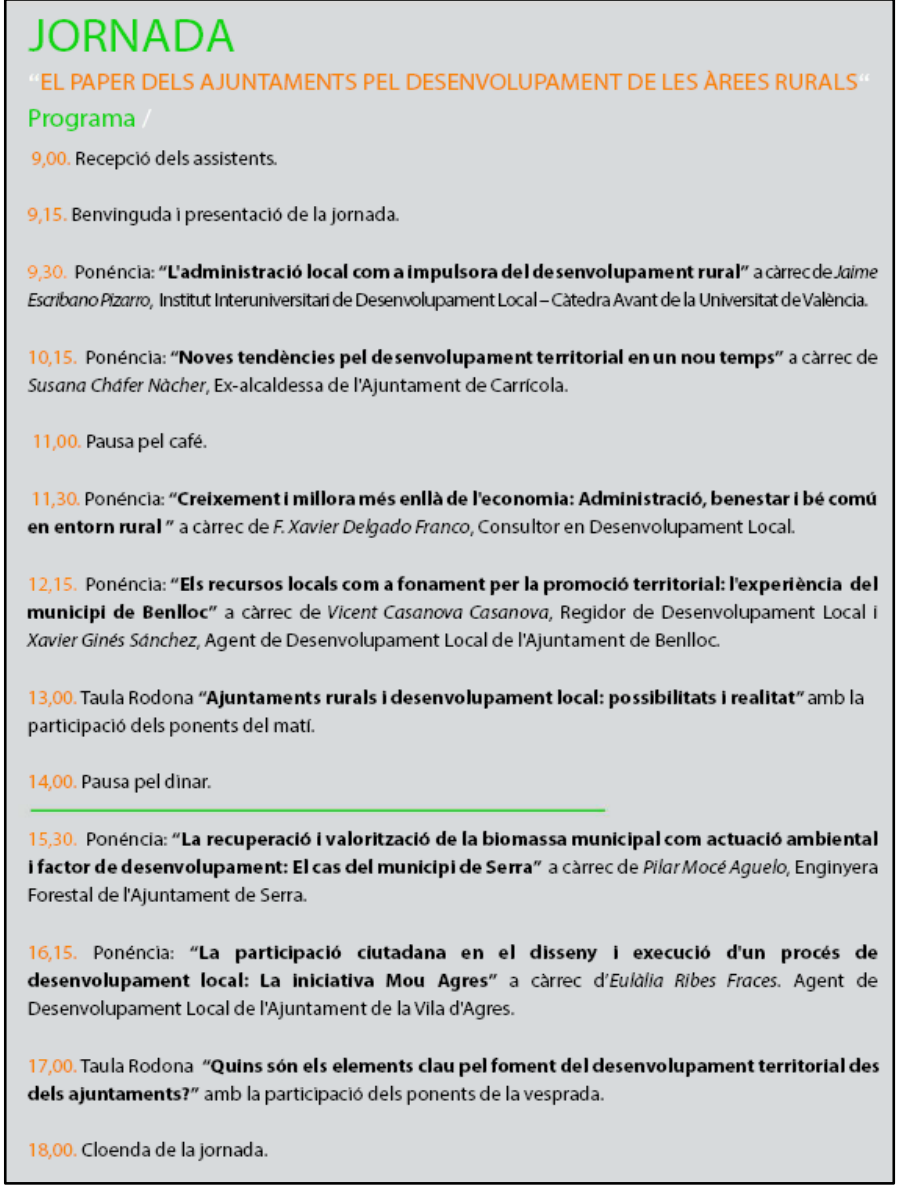

Acto seguido, el ponente Xavier Delgado Franco, ante la imposibilidad de acudir a la jornada de la alcaldesa invitada, improvisó una ponencia sobre la experiencia del municipio de Carrícola, en la comarca de la Vall d'Albaida. A continuación, se mostró cómo un pueblo de tan sólo 90 habitantes, en el que la agricultura ecológica hizo acto de presencia desde la década de 1980, se había apostado por la sostenibilidad, la educación medioambiental y la reflexión sobre impacto que la población pudiera tener sobre el territorio. Así, su apuesta por la agricultura ecológica les había permitido acceso tanto a mercados externos especializados como a mercado de proximidad. También habían puesto en valor recursos patrimoniales como un acueducto islámico y habían

decidido crear un hostal público (de gestión privada) para que incrementaran las pernoctaciones en un pueblo que, sorprendentemente para su tamaño, goza buen número de visitas que llegan atraídas por sus festivales y su modo de vida fuera de lo convencional. Siguiendo en la línea del desarrollo sostenible, Delgado mostró cómo Carrícola empleaba una fitodepuradora para depurar sus "aguas grises" y realizaba recogida de residuos selectiva, haciendo uso de una compostera para reutilizar todos los residuos orgánicos (y ahorrándoles muchos costes en recogidas). Particularmente interesante nos pareció el hecho de que Carrícola contara con seis asociaciones todas ellas en activo, algo que Delgado insistió en recalcar era crucial para generar bienestar, como sabemos empíricamente desde el seminal Making Democracy Work de Putnam (1993). Este hecho, volvió hacer acto de presencia en la ronda de preguntas, como contestación a la intervención de una mujer del público que venía de un pueblo de 250 habitantes que afirmaba que «es que hay muy poca población. Es como si hubiéramos llegado tarde. Desde los 70s generaciones enteras se fueron a Valencia o Castellón. Es como si hubiéramos llegado tarde». A lo cual Delgado contestó, en relación con el capital social, 
que «si tienes 50 personas y son 50 activistas [el pueblo] "funciona como un tiro", y si hay 500 y dos activistas nada. Tiene que ver con la comunidad local, su historia. Hay que empoderarla. El político se va, pero la sociedad civil se queda. Si la sociedad civil está activa el pueblo se mueve. No es un problema de despoblación, sino de quién está». De nuevo brillante ante una pertinente intervención del público que se preocupaba —al imaginar las condiciones de Carrícola aplicadas a su municipio - por la posibilidad de que los pueblos devinieran "parques de atracciones" sin servicios públicos efectivos, Delgado puso de relieve que precisamente cada solución de desarrollo local debe de estar adaptada a las condiciones específicas de cada territorio, y que nadie dijo nunca que las mismas prácticas fueran extrapolables en su literalidad, sino más bien como ejemplos de buenas prácticas de los que tomar ideas.

Tras la pausa del café Xavier Delgado volvió a tomar la palabra, esta vez con la ponencia para la cuál había sido programado originariamente, titulada "Creixement i millora més enllà de l'economia: Administració, benestar i bé comú a l'entorn rural'. En ella, ahondando en los problemas de financiación sufridos por los municipios como resultado de un marco legal y administrativo muy poco favorable a la población rural, Delgado mostró nuevas formas de economía que tienen como objetivo aportar bienestar, no ser un fin en sí mismas. Así, la economía del bien común fue presentado por Delgado como respetuosa de la dignidad, la sostenibilidad, y fomentadora de la participación. Tras la muestra de una serie de buenas prácticas la ponencia concluyó con una reflexión que invitaba a meditar a los asistentes sobre la dificultad del acceso al crédito en los pueblos, dada la desaparición de las tradicionales cajas de ahorro, y cómo ese afectaba al emprendimiento, algo que nuestro grupo de universitarios pudo comprobar desde la misma llegada a Algímia d'Alfara esa misma mañana para las jornadas, al comprobar que no había un solo cajero automático en todo el pueblo.

El siguiente turno fue para el tándem de cargo político y agente de desarrollo local (ADL) formado por Vicent Casanova Casanova y Xavier Ginés Sánchez, en su charla-ponencia titulada "Nuevas tendencias para el desarrollo territorial en un nuevo tiempo". En ella, reflexionaron en tono de conversación, respecto a la experiencia de ambos en el municipio de Benlloch, en la provincia de Castellón (Figura 1). Ambos coincidían en que gran parte de la labor de un ADL en el medio rural tiene que ver con «animar el espíritu local, crear conciencia de que se pueden hacer en el pueblo ciertas cosas que no se pensaban posibles». Dada la inadecuación al medio rural del marco normativo Casanova opinó que la concienciación de la ciudadanía es el factor clave del desarrollo, basándose en potenciar en la ciudadanía un discurso de «qué queremos ser de mayores» y «qué modelo de pueblo queremos tener». Precisamente sobre este aspecto de la concienciación incidió también Ginés en relación a la impugnación — de nuevo- de la dicotomía rural-urbano. El problema residía según él en que la ciudadanía de los pueblos había aceptado el relato de lo rural ("bonito", "verde", auténtico", sostenible") de la ciudad, hecho que no permitía que se desarrollara su verdadero potencial. Parar revertir esta situación cabría «crear conciencia política [mediante la] reivindicación de saberes locales, la erradicación del auto-odio y una redefinición lo rural, haciéndolo positivo más allá de lo bucólico». En particular en Benlloch, en ausencia de recursos turísticos clásicos, y demostrando que los productos turísticos son socialmente construidos (Pitarch, 2016), se decidió «trabajar mucho la cultura por todas las vías, como espíritu crítico y reivindicativo de lo local (nuestra lengua es el valenciano)» siendo el exponente más claro de esta aproximación al desarrollo local el exitoso festival de música en valenciano Festlloc, que se organiza en una cooperación público-privada con Escola en Valencià. Ya en la mesa redonda, se aportaron dos claves más: plantear objetivos de cooperación realistas a la ciudadanía para 
que puedan ser alcanzados y por tanto ésta no se desanime, y una vez más el compromiso para con el desarrollo de tal suerte que sea contagioso para la ciudadanía, afirmando Casanova «lo primero de todo es que nos lo tenemos que creer nosotros mismo, [los políticos]».

Figura 1. Mesa redonda

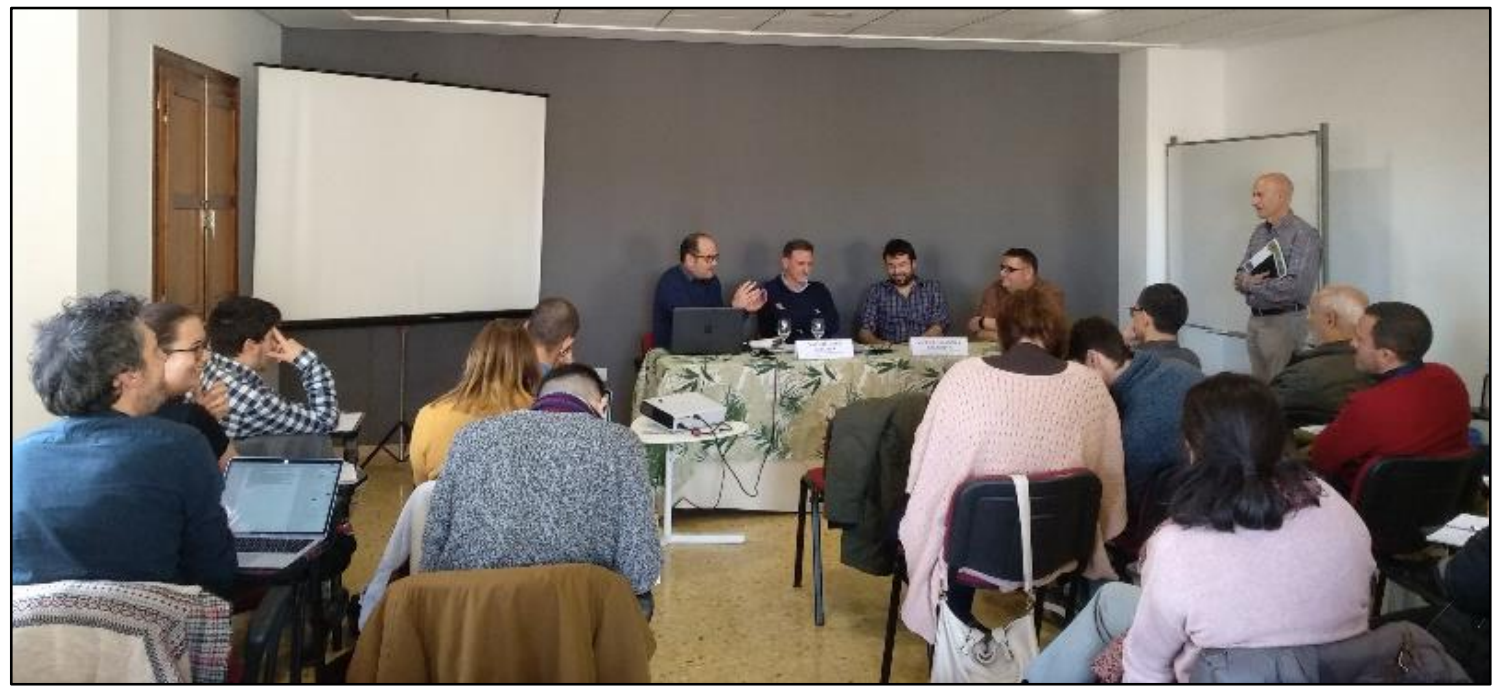

Fuente: Xavier Sirera Genís. 29 de noviembre de 2019. Algimia d'Alfara (Valencia)

A continuación, tuvo lugar la ponencia "La recuperación y valorización de la biomasa municipal como actuación ambiental y factor de desarrollo: (Life resilient forest)" a cargo de Pilar Mocé Aguelo, ingeniera forestal del Ayuntamiento de Serra. Esta ponencia, por su carácter más técnico, ahondó menos en factores estrictamente relacionados con prácticas que venimos asociando al desarrollo local, y sin embargo su ponencia suscitó muchos intereses entre los asistentes a colación de la gestión de restos de agrícolas y de jardinería de cara las normativas europeas que pronto prohibirán la práctica de las quemas. Básicamente, el plan mostrado por Mocé consistía en la zonificación de toda el área forestal del término municipal de Serra de cara a realizar planes de "cortas" cada 10 años, así como recogidas de árboles muertos o enfermos y el cuidado de los "pimpollares". Mediante estas prácticas, que previenen los incendios, el Ayuntamiento creó toda una infraestructura de creación de pellets de diversas calidades para autoconsumo en los edificios municipales con calefacción por caldera, así como venta de excedentes a poblaciones vecinas. Junto con la recogida y triturado de restos agrícolas, el municipio consigue haber erradicado la quema de restos agrícolas, y ha creado dos puestos de trabajos fijos y dos temporales. En términos económicos Mocé afirmó que el ahorro en combustible para las calderas vendría a equivaler lo gastado en los cuatro operarios que el sistema requería, pero eso sí, con la consecuente fijación de población al territorio que ello conlleva, así como la prevención de incendios que el proyecto implica.

Por último, creemos que vale la pena afirmar que la ponencia de la ADL del municipio de Agres, Eulàlia Ribes Faes, titulada "La participación ciudadana en el diseño y ejecución de un proceso de desarrollo local: la iniciativa Mou Agres", fue todo un exponente de los que hemos considerado nuestra tesis central, esto es: que el desarrollo local sólo es exitoso cuando quién anima a ello a la ciudadanía cree en ello y actúa con la certidumbre - la tenga o no- de que es lo mejor para el pueblo y de que el éxito está 
garantizado. La iniciativa Mou Agres, inscrita dentro de la Agenda 21, fue aceptada por el nuevo gobierno entrante al consistorio, el cual tenía claro que «había que activar a la ciudadanía, de manera que la ciudadanía sintiera suyos los proyectos del nuevo gobierno». De esta forma se diseñó el plan estratégico participativo, que Ribes recordó tendría aspectos positivos, como que las decisiones que se tomaran tendrían el apoyo de ciudadanía, así como negativos, pues la ciudadanía podría tomar decisiones que no agradaran al gobierno. En cualquier caso, el mandato era claro: generar reflexión en ciudadanía respecto de «qué necesitas de tu pueblo». Ribes detalló todas las fases del proceso participativo con un entusiasmo contagioso, que hacía imposible dudar respecto del éxito que la iniciativa tuviera en Agres. Y así fue, pues los índices de participación llegaron al 15\%, manteniendo participativo y crítico a un pueblo que se había reactivado políticamente al punto de propiciar un cambio de gobierno y dotando de legitimidad las ediciones colectivas tomadas, todo un hito, aun a escala municipal dada la creciente desafección presentada en las democracias liberales occidentales (Mair, 2013).

En resumen, un sinfín de ideas y ejemplos de casos exitosos para hacer que la innovación, la participación y la cooperación herramientas eficaces en la lucha por conseguir que se pueda gozar de los mismos derechos en los pueblos que en las ciudades de tal modo que merezca la pena vivir en ellos. Y de nuevo, una lección: el carisma y la iniciativa de un ADL, así como de cuánto crea este o esta en el proyecto de desarrollo y su capacidad de "contagiar" ese entusiasmo a la ciudadanía serán - a nuestro juicio - factores determinantes en el éxito de todas las iniciativas emprendida en pos de desarrollo local.

\section{REFERENCIAS}

Borges, J. L. (2004). Ficciones. Alianza Editorial.

Mair, P. (2013). Ruling The Void. The Hollowing of Western Democracy. Verso.

Pitarch, M. D. (2016). Implicaciones del turismo en el desarrollo local. El papel estratégico de los recursos territoriales turísticos. En J. Noguera (coord.), La visión territorial y sostenible del desarrollo local: Una perspectiva multidisciplinar (pp. 341-363). Vol. 1. Publicacions de la Universitat de València-SEBRARE.

Putnam, R. (1993). Making Democracy Work. Civic Traditions in Modern Italy. Princeton University Press.

Buenaventura Marco Moreno

Graduado en Ciencias Políticas y de la Administración Pública

Universitat de València

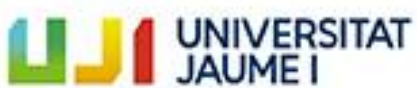

Institut Interuniversitari de Desenvolupament Local
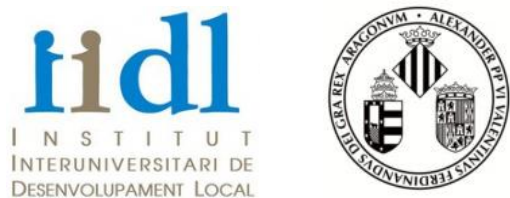

VNIVERSITAT (E) ValènCia 